University of Nebraska - Lincoln

DigitalCommons@University of Nebraska - Lincoln

USDA Wildlife Services - Staff Publications

U.S. Department of Agriculture: Animal and Plant Health Inspection Service

2018

Development and Evaluation of a Bait Station for Selectively

Dispensing Bait to Invasive Wild Pigs

\author{
Michael Lavelle \\ USDA, Animal and Plant Health Inspection Service, michael.j.lavelle@aphis.usda.gov \\ Nathan P. Snow \\ USDA, Animal and Plant Health Inspection Service, nathan.p.snow@aphis.usda.gov \\ Joe M. Halseth \\ USDA, Animal and Plant Health Inspection Service \\ John C. Kinsey \\ Kerr Wildlife Management AreaTexas Parks and Wildlife Department \\ Justin A. Foster \\ Kerr Wildlife Management AreaTexas Parks and Wildlife Department
}

See next page for additional authors

Follow this and additional works at: https://digitalcommons.unl.edu/icwdm_usdanwrc

Part of the Life Sciences Commons

Lavelle, Michael; Snow, Nathan P.; Halseth, Joe M.; Kinsey, John C.; Foster, Justin A.; and VerCauteren, Kurt C., "Development and Evaluation of a Bait Station for Selectively Dispensing Bait to Invasive Wild Pigs" (2018). USDA Wildlife Services - Staff Publications. 2111.

https://digitalcommons.unl.edu/icwdm_usdanwrc/2111

This Article is brought to you for free and open access by the U.S. Department of Agriculture: Animal and Plant Health Inspection Service at DigitalCommons@University of Nebraska - Lincoln. It has been accepted for inclusion in USDA Wildlife Services - Staff Publications by an authorized administrator of DigitalCommons@University of Nebraska - Lincoln. 


\section{Authors}

Michael Lavelle, Nathan P. Snow, Joe M. Halseth, John C. Kinsey, Justin A. Foster, and Kurt C. VerCauteren 
Original Article

\title{
Development and Evaluation of a Bait Station for Selectively Dispensing Bait to Invasive Wild Pigs
}

\begin{abstract}
MICHAEL J. LAVELLE, ${ }^{1}$ U.S. Department of Agriculture/Animal and Plant Health Inspection Service/Wildlife ServicesNational Wildlife Research Center, 4101 LaPorte Avenue, Fort Collins, CO 80521, USA

NATHAN P. SNOW iD, U.S. Department of Agriculture/Animal and Plant Health Inspection Service/Wildlife ServicesNational Wildife Research Center, 4101 LaPorte Avenue, Fort Collins, CO 80521, USA

JOE M. HALSETH, U.S. Department of Agriculture/Animal and Plant Health Inspection Service/Wildife ServicesNational Wildife Research Center, 4101 LaPorte Avenue, Fort Collins, CO 80521, USA

JOHN C. KINSEY, Kerr Wildlife Management AreaTexas Parks and Wildlife Department, 2625 Farm-to-Market 1340, Hunt, TX 78024, USA

JUSTIN A. FOSTER, Kerr Wildlife Management AreaTexas Parks and Wildlife Department, 2625 Farm-to-Market 1340, Hunt, TX 78024, USA

KURT C. VerCAUTEREN, U.S. Department of Agriculture/Animal and Plant Health Inspection Service/Wildife ServicesNational Wildife Research Center, 4101 LaPorte Avenue, Fort Collins, CO 80521, USA
\end{abstract}

\begin{abstract}
Populations of invasive wild pigs (Sus scrofa; hereafter, wild pigs) are expanding, requiring costeffective tools for control, and disease prevention, such as toxic or vaccine baits. Specifically, development of a novel and humane toxicant is underway for control of wild pigs in the United States and Australia. A speciesspecific bait station for delivering the toxic bait must be used to protect nontarget animals. Further, a bait station must be designed to maximize feeding by wild pigs by accommodating their group-feeding behaviors. We sought to develop a bait station that delivered bait to the maximum proportion of wild pigs and excluded the most ubiquitous nontarget species, specifically white-tailed deer (Odocoileus virginianus) and raccoons (Procyon lotor). We used direct observations and cameras during 2015 to evaluate wild pig feeding behavior and nontarget access for various sizes, arrangements, and construction materials of prototype bait stations in pen and field settings in Texas, USA. We found that a bait station constructed of 2 back-to-back troughs, $1.1 \mathrm{~m}$ in length, without a divider was sufficient for feeding the largest proportion of wild pigs in pens. Using this design of bait station at 30 field sites, we found that wild pigs fed more frequently from plastic than metal bait stations, although both bait stations reduced feeding by wild pigs compared with control sites. From near-video imagery at 3 field sites, we identified that $80 \%$ of wild pigs ( 33 of 41 ), $0 \%$ of white-tailed deer ( 0 of 7 ), and $17 \%$ of raccoons ( 1 of 6 ) accessed the bait stations on the final night of testing following a 2 -week acclimation and training period. Future steps toward development of a wild pig-specific bait station include adding resistance to the lids of bait stations to completely exclude raccoons and identify baiting strategies that most efficiently acclimate wild pigs to using bait stations. Published 2018. This article is a U.S. Government work and is in the public domain in the USA.
\end{abstract}

KEY WORDS bait station, delivery, feral swine, nontarget risk, pharmaceutical, Sus scrofa, toxic bait, wild boar.

Invasive wild pigs (Sus scrofa), also referred to as feral hogs, feral pigs, feral swine, or wild boars (Keiter et al. 2016), are a nonnative species that exist in $\geq 38$ states of the continental United States (McClure et al. 2015) and are spreading (Snow et al. 2017b). Populations of wild pigs continue to expand because of their adaptability and high reproductive potential, and because they are translocated for hunting purposes and released by humans (Bevins et al. 2014). Today, wild pigs are the most abundant introduced ungulate in the United States (Feldhamer and McCann 2004). Their damage to natural

Received: 28 February 2017; Accepted: 24 November 2017 Published: 10 March 2018

${ }^{1}$ E-mail: michael.j.lavelle@aphis.usda.gov and agricultural resources can be substantial (Seward et al. 2004, Stankus 2012). For example, estimated costs associated with managing wild pig-related issues in the United States was conservatively estimated to exceed US\$1 billion/year (Pimentel 2007, Stankus 2012). Further, wild pigs carry a variety of diseases that are transmissible to humans and domestic livestock (Wyckoff et al. 2009, Campbell et al. 2011a, Bevins et al. 2014). Given the precipitous increase in abundance and distribution of wild pigs and subsequent rise in human conflicts (Mayer and Brisbin 2009), it is apparent that current methods of control are not capable of large-scale elimination of wild pigs (Burton et al. 2013). More effective methods or modifications to existing methods are needed (Campbell and Long 2009, Mayer and Brisbin 2009). 
Given the current status of wild pigs in the United States, alternative management strategies are being pursued. Delivery of pharmaceuticals including toxicants, contraceptives, and vaccines is being evaluated, with an emphasis on developing delivery strategies that minimize risk to nontarget species (Cowled et al. 2008, Ballesteros et al. 2009, Bengsen et al. 2011, Kittawornrat and Zimmerman 2011). For example, Kaput ${ }^{\mathbb{R}}$ (Scimetrics Ltd. Corp. Wellington, CO, USA), a warfarin-based toxic bait, was recently registered for use on wild pigs in the United States by the Environmental Protection Agency (EPA Registration \#72500-26) although it is not yet being used in the field operationally (Frey 2017, Snow et al. 2017a). Development of another toxic bait containing the active ingredient sodium nitrite (HOGGONE ${ }^{\circledR}$; Animal Control Technologies Australia P/L, Somerton, Victoria, Australia) for removing wild pigs is underway through a collaborative effort by the U.S. Department of Agriculture, Texas Parks and Wildlife Department, Invasive Animals Cooperative Research Center, Connovation Ltd, and Animal Control Technologies Australia (Snow et al. 2016, 2017a,c). An important component of this research is the development of a bait station that can effectively limit access by nontarget species while allowing access by wild pigs. For development of a new bait station, capabilities of wild pigs and ubiquitous nontarget species such as raccoons (Procyon lotor) and whitetailed deer (Odocoileus virginianus) must be considered simultaneously to maximize efficacy and minimize nontarget risks (Snow et al. 2017c). For wild pigs to gain access to bait stations, they must intentionally open lids that are designed to inhibit access by raccoons (Snow et al. 2017c). In previous research, the optimal level of magnetic resistance of 13.6$18.1 \mathrm{~kg}$ was established for securing lids closed. This resistance excluded all raccoons, yet allowed access by most wild pigs (Snow et al. 2017c). American black bears (Ursus americanus) also represent a challenging nontarget species in the United States that will require further baitstation refinement, but have a smaller geographic distribution and exist in lower densities than raccoons and may be more avoidable by careful selection and monitoring of bait sites (McLean and Pelton 1994, Pelton and Van Manen 1994, Boersen et al. 2003).

Information on behavior of wild pigs at bait stations is lacking, though documented behaviors of domestic pigs at feeding stations suggest that challenges exist for overcoming aggressive behaviors by dominant individuals that limit feeding by subordinates (Nielsen et al. 1995, 1996). When feeding as a group, domestic pigs express aggressive behaviors that enable them to feed based on social ranking (Held et al. 2000, 2002). Additionally, wild pigs are social animals typically found in groups of 3-9 animals (Mayer and Brisbin 2009). Wild pigs within these groups forage together, so a bait station should accommodate groupfeeding behaviors by providing access to multiple wild pigs (Focardi et al. 2015).

Bait stations have been designed and tested previously for wild pigs (Long et al. 2010; Massei et al. 2010; Campbell et al. 2011b, 2013). These designs successfully allowed access by wild pigs and excluded most nontargets, but experienced reduced consumption of bait by wild pigs and occasional nontarget use (Long et al. 2010, Campbell et al. 2013). Also, the design of previous bait stations was focused on delivery of dry, pelletized, or granular bait with potential to flow downward from a hopper to a feeding trough (Long et al. 2010, Campbell et al. 2011b, Lapidge et al. 2012, Ferretti et al. 2014). HOGGONE ${ }^{\circledR}$ consists of peanut paste and crushed grains (Shapiro et al. 2016, Snow et al. 2016) and does not flow like pelletized or granular baits. As such, a new bait-station design that provides access to the majority of visiting wild pigs, excludes nontargets, and lends itself to delivery of a paste bait is needed.

Our objectives were to 1) develop a prototype bait station that maximized feeding and minimized aggressive behaviors by captive wild pigs in pens and 2) then test this prototype in the field to ensure that free-ranging wild pigs gained access and nontarget species were excluded. Specifically, we tested multiple sizes and arrangements of bait stations on captive wild pigs to identify the most effective design for maximizing group-feeding. Then, we tested plastic versus metal versions of the best bait station on free-ranging wild pigs in a field setting to compare access by free-ranging wild pigs and exclusion of nontargets.

\section{STUDY AREA}

We conducted pen trials during June 2015 within the Texas Parks and Wildlife Feral Swine Research Facility, a 6-ha, fenced subsection of the $26.3-\mathrm{km}^{2}$ Kerr Wildlife Management Area (WMA) west of Hunt, Texas, USA. Field trials were conducted at nearby Camp Bullis $\left(112.9 \mathrm{~km}^{2}\right)$, which was a military property operated by Joint Base San Antonio, Texas, USA. Kerr WMA was on the Edwards Plateau, and Camp Bullis straddled the Edwards Plateau and Blackland Prairie ecoregions of the south-central semiarid prairies of Texas (Bailey 1980, 1998). Average daily temperature during the study varied from $17.2^{\circ}$ to $27.5^{\circ} \mathrm{C}$ at the Kerr WMA and $22^{\circ}$ to $30.7^{\circ} \mathrm{C}$ at Camp Bullis (Local Climatological Data Summaries for Bexar and Kerr Counties; Apr through Sep 2015; National Climatic Data Center 2017). Average daily precipitation was $0-2.79 \mathrm{~mm} /$ day in Hunt and $0-8.13 \mathrm{~mm}$ in San Antonio from April to September 2015. Population control of wild pigs had not been conducted for 3-5 years prior to study, with the exception of limited recreational hunting on Camp Bullis. Both properties had restricted access and were surrounded by perimeter fencing.

\section{METHODS}

\section{Pen Study}

We used captive wild pigs in pens to experimentally test different sizes (Phase 1) and arrangements (Phase 2) of troughs. Specifically, we evaluated the size and arrangement that minimized aggressive behavior and maximized access by wild pigs. We conducted Phases 1 and 2 in $410 \times 10$-m pens. We captured all captive pigs from free-range populations and relocated them to the study site. On the first day of each phase, we randomly selected 5 captive pigs for each pen, from 
within a larger holding pen ( $2 \mathrm{ha})$, using a livestock chute and handling system. Within the holding pen, we provided wild pigs a maintenance diet of $18 \%$ Sow Ration Pellet (AC Nutrition, Winters, TX, USA) offered at approximately $1.8 \%$ of group body mass daily and dispensed from automatic feeders, and we provided water ad libitum. We selected animals weighing $20-40 \mathrm{~kg}$ for the safety of study animals and researchers. We also selected animals to have no $>3$ males or females in each pen, respectively. Using unique combinations of ear tags (All American ${ }^{\circledR}$ 2-piece tags; YTex Corp., Cody, WY, USA), livestock marking paint (Swine Shot ${ }^{\circledR}$ Spray Paint; LA-CO Industries Inc., Elk Grove Village, IL, USA), and uniquely patterned collars (Duck Tape ${ }^{\mathbb{R}}$; ShurTech Brands LLC, Avon, OH, USA), we marked all wild pigs to identify individual animals. We randomly assigned groups of 5 animals into 1 of the 4 pens. We selected and marked new animals at the beginning of Phase 1 and Phase 2.

Once we moved the groups of wild pigs into corresponding pens, all animals remained together in that pen for a 4-day evaluation period. We increased motivation to access the troughs by reducing the daily rations to $70 \%$ of normal maintenance diet (Angermeier et al. 1987, Day et al. 1995, Seaman et al. 2008). We divided the rations equally among troughs when $>1$ trough was present in a pen. In the morning of each trial day, we temporarily vacated wild pigs from their respective pens and set the respective treatment troughs into place in the center of each pen, along with cameras (Reconyx PC900; Reconyx, Inc., Holmen, WI, USA) aimed directly at the troughs. We set cameras to timelapse mode to record an image every $15 \mathrm{~s}$ regardless of activity by wild pigs, and left them active for $12 \mathrm{hr}$ following placement of troughs. Once troughs and cameras were placed, we restored wild pigs back into their respective pen and began trials.

We recorded data from 2 sources for each feeding bout. A feeding bout began when a wild pig opened the lid of the trough and ended when the lid closed. From cameras, we recorded the count of single-animal feeding events (i.e., no. of times one animal accessed the bait station), and the count of multianimal feeding events (i.e., no. of times $>1$ animal accessed the bait station simultaneously) during each feeding bout. Secondly, one visual observer per pen was situated in 3.05-m elevated tripod blind adjacent to each pen and recorded data for $4 \mathrm{hr}$ after introduction of troughs. Observers recorded the count of times each animal fed from a trough during a trial, and count of times each animal aggressively stole the trough from another animal. We counted feeding anytime an animal used its head or snout to open and access the trough, or nonaggressively shared access after another animal opened the trough. We counted stealing anytime an animal aggressively displaced another animal that had previously opened the trough.

Phase 1.-This phase of the pen study was a comparison of 4 lengths of troughs, with the goal of determining the length that maximized access by the most animals simultaneously. We constructed troughs for this phase of 3.8-cm-thick, untreated pine lumber with a horizontally mounted, hinged lid on the top providing access to the reservoir below. All troughs were $40.6 \mathrm{~cm}$ wide (front-to-rear) and $25.4 \mathrm{~cm}$ deep (top-to-bottom). We constructed the hinged lid from 18.3$\mathrm{mm}$ cabinet-grade plywood with a $10.1-\mathrm{cm}$ rounded lip overhanging the frame of the trough on the front and sides to facilitate wild pigs opening it with their snout. We securely attached each trough to a $1.22-\mathrm{m}^{2}$ piece of plywood to prevent it being flipped over by wild pigs. To determine

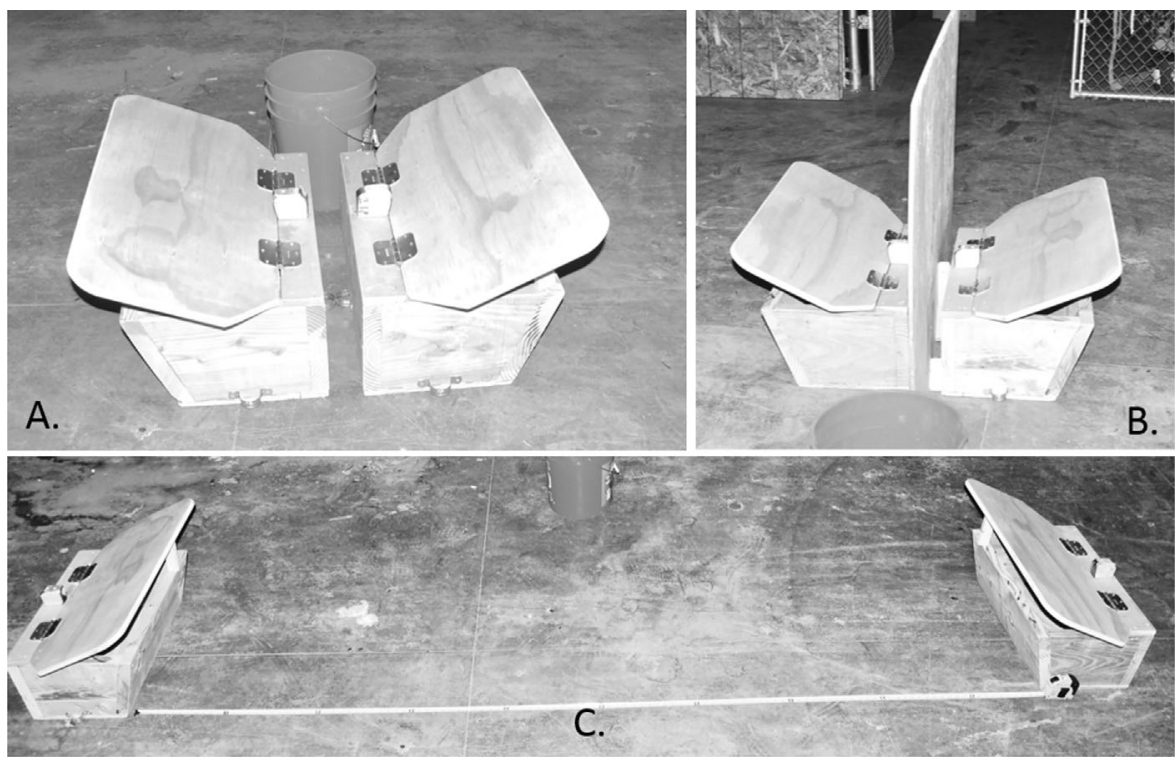

Figure 1. Prototype bait stations designed to evaluate optimal arrangement to maximize potential for feeding by multiple invasive wild pigs simultaneously in controlled trials with captive wild pigs in June 2015, at the Kerr Wildlife Management Area, Hunt, Texas, USA. Prototype bait stations were built $1.1 \mathrm{~m}$ in length based on results from Phase 1 length evaluations and consisted of 3 arrangements: A. pair of troughs situated touching back-to-back and opening in opposing directions, B. pair of troughs situated touching back-to-back though separated by a $1.2 \times 2$-m plywood visual divider and opening in opposing directions, and C. pair of troughs situated $3 \mathrm{~m}$ apart and opening to a shared central point. 
which length enabled the greatest number of wild pigs to feed side-by-side under one lid, we constructed troughs of 4 arbitrarily selected lengths $(0.3,0.6,1.1$, and $1.9 \mathrm{~m})$.

On the 1 st day of testing for Phase 1 , we randomly assigned one of the 4 different length troughs to each of the 4 pens, respectively. On subsequent days, we systematically rotated the troughs through each pen so that all groups of wild pigs were exposed to each length of trough for 1 day. We left the troughs in each pen for $12 \mathrm{hr}$ and removed them at night.

Phase 2.-The second phase of the pen study built on results from Phase 1. We constructed bait stations used in Phase 2 as in Phase 1 based on the optimal trough length determined during that phase, and incorporated into 3 unique arrangements of a pair of identical troughs in an effort to determine the resulting bait-station arrangement that maximized simultaneous access by the most animals (Fig. 1). We assigned these 3 treatment arrangements similarly and rotated through the 4 pens as in Phase 1.

\section{Field Study}

We used optimal length and arrangement of troughs as determined in the pen study to inform the development of a prototype bait station for field testing. We constructed 2 sets of prototype bait stations for field-testing from materials that would be durable in field settings: marine-grade high-density polyethylene plastic and powder-coated steel (Fig. 2). Specifically, we evaluated selection by free-ranging wild pigs for either material as evidenced by their use of the bait stations. We also subjectively evaluated the feasibility of the 2 materials for a user-friendly field deployment. Lastly, we recorded and compared temperatures inside bait stations constructed of each material and with ambient temperatures.

We randomly selected deployment sites in areas that represented habitat for wild pigs (Mayer and Brisbin 2009, Thurfjell et al. 2009). We used the 2006 National Land Cover Database to identify areas with trees, shrubs, and grass-dominated land covers. We excluded land covers that represented developed, open water, and barren areas. We also excluded areas that were $<300 \mathrm{~m}$ from buildings and $<100 \mathrm{~m}$ from roads. Finally, we excluded sensitive areas including the core areas of endangered golden-cheeked warblers (Setophaga chrysoparia; DeBoer and Diamond 2006), karsts and caves,

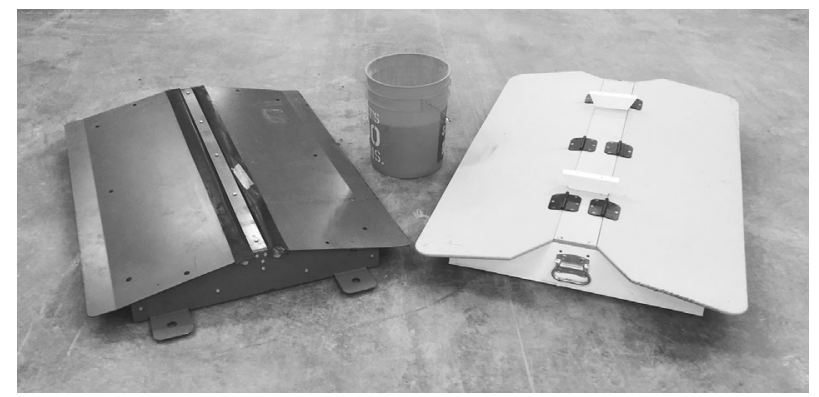

Figure 2. Prototype bait stations for invasive wild pigs designed to enable the evaluation of materials (metal or plastic) to construct a bait station that would maximize feeding by multiple individuals simultaneously in field trials with free-ranging wild pigs in September 2015, at Camp Bullis, San Antonio, Texas, USA. and restricted cultural areas. The remaining areas available for study covered $46.4 \mathrm{~km}^{2}$ of Camp Bullis. We generated 51 random sites using the Spatially Balanced Points tool (ArcGIS v10.2; ESRI, Redlands, CA, USA) for Camp Bullis. To reduce dependency among sites, we selected all points to be $\geq 300 \mathrm{~m}$ apart, but they averaged $725.1 \mathrm{~m}$ apart $(\mathrm{SD}=480.0)$. After a prebaiting period at each site to attract wild pigs, we eliminated 11 sites because of inconsistent visitation by wild pigs.

We randomly assigned the remaining 40 sites to 1 of 3 treatments: 1) untreated control $(n=10), 2)$ metal bait station $(n=10)$, and 3$)$ plastic bait station $(n=20)$. We subdivided the treatment of plastic bait stations into treatments where we did $(n=10)$ and $\operatorname{did} \operatorname{not}(n=10)$ fully close the lids of the bait stations to examine whether fully closing the lids deterred nontarget species or affected access by wild pigs because this represented our first testing in a field setting. Control sites did not receive bait stations, but we placed bait on the ground to serve as a reference for treatments at each step of the study.

We offered and maintained $20 \mathrm{~kg}$ of whole-kernel corn as bait at each site for 15 nights by refreshing the bait daily (Fig. 3). We used nights 1-6 as a prebaiting period during which we placed bait on the ground at all sites to initially attract wild pigs. For night 7 , we placed the bait stations at each of the respective sites. During nights 7-9, we wired the lids of the bait stations open $(\sim 40 \mathrm{~cm})$ providing easy access to bait in the bait station. During nights 10-13, we lowered the lids to approximately $5.25 \mathrm{~cm}$ so that wild pigs were required to contact lids of the bait stations to access the bait inside. During nights $14-15$, we closed the lids of the 10 plastic bait stations that represented the treatment of fully closed bait stations, and all other bait stations remained propped at approximately $5.25 \mathrm{~cm}$. At treatment sites, we placed all bait inside of the bait stations. Additionally, we placed a small amount of corn $(\sim 1 \mathrm{~kg})$ under the outsidefront lip of each lid starting on night 13 in attempt to increase

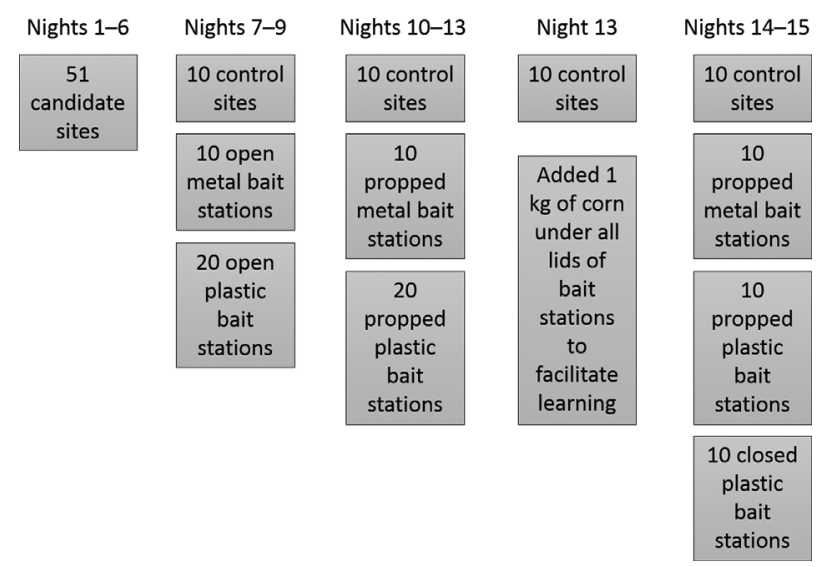

Figure 3. Study schedule for field trial designed to determine the ideal material (plastic or metal) for constructing a bait station that would maximize feeding by multiple individuals simultaneously in field trials with free-ranging invasive wild pigs in September 2015, at Camp Bullis, San Antonio, Texas, USA. 
searching under the lids by wild pigs. We baited control sites identically to treatment sites although we offered bait on the ground instead of in a bait station.

We monitored each site using cameras (RECONYX PC900) mounted on T-posts or trees by capturing single images at time-lapse intervals of $5 \mathrm{~min}$. We mounted the cameras facing north $5 \mathrm{~m}$ from the bait, $1.5 \mathrm{~m}$ above the ground, and an angle of $70^{\circ}$ to provide consistent field of view at each site that was approximately $12-\mathrm{m}$ long $\times 8-\mathrm{m}$ wide. We monitored a random subset of 3 sites/treatment using a second camera recording a near-video rapid burst of 40 images separated by $15 \mathrm{~s} /$ motion-activated trigger. We used these series of images to make inference about the true proportion of animals that gained access to bait stations when lids of bait stations were closed.

Lastly, we were concerned that temperatures inside bait stations may become hot and aversive to animals. Therefore, we deployed 18 temperature data loggers (EasyLog USB Dataloggers, Model EL-USB-1; Lascar Electronics, Inc., Erie, PA, USA) evenly distributed throughout treatments and controls. We recorded the internal temperatures $\left({ }^{\circ} \mathrm{C}\right)$ every 30 min throughout the study at the midpoint within bait stations and ambient air temperature at control sites. The Institutional Animal Care and Use Committee of the National Wildlife Research Center (NWRC, QA-2263) approved all procedures.

\section{Data Analysis}

For Phase 1 of the pen study, we analyzed data collected only with cameras because one pen of pigs did not consume food until after the observers vacated the area. First, we evaluated the effect of the treatment troughs on the counts of multianimal feeding events. We evaluated trough length for the trough that maximized multianimal feeding events as a means of measuring increases in cooperative feeding behavior per pen. Second, we evaluated the effect of the treatment troughs on the counts of single-animal feeding events. We assessed the trough length that minimized single-animal feeding events as a means of measuring reductions in competitive feeding behaviors per pen. We used Poisson generalized linear models with log links in Program R ( $\mathrm{glm}$ in base package; v 3.3.1, R Development Core Team, Vienna, Austria), and with offsets for the number of 15-s time-lapse photos that were taken during each trial as a surrogate measure of time. The offsets were used to account for differences in trial lengths based on the durations of first feeding until all food was consumed. We examined the 95\% confidence intervals $(\mathrm{CI})$ surrounding the regression coefficients $(\beta)$ for lack of overlap with zero to provide evidence of differences among treatments.

For Phase 2 of the pen study, we analyzed data collected by visual observers because all animals used the troughs while visual observers were present. Visual observers collected data until all of the food within the troughs was consumed. First, we examined the 3 arrangements of troughs for evidence of increasing the frequency of feeding per animal to assess which arrangement maximized feeding. Second, we examined these arrangements for evidence of reducing the frequency of animals aggressively displacing others from a trough to assess which arrangement minimized competitive behaviors. We used Poisson generalized linear effect models with log links and offsets for the number of 15-s time-lapse photos that were taken during each trail as a surrogate measure of time.

For the field study, we processed all time-lapse images using the Colorado Parks and Wildlife Photo Warehouse Database (Ivan and Newkirk 2015). For each image, we recorded date, time, number of each species present, and number of those animals that were consuming bait. We aggregated these data for each species into unique feeding bouts for analysis. We considered a unique feeding bout as any visitation to the bait separated by 30 -min quiet periods without that species present. For each feeding bout, we identified the maximum number of each species present during the bout by identifying the image(s) with the greatest number of each species. We also identified the maximum number of each species observed consuming the bait during each feeding bout by identifying the image(s) with the greatest number of each species consuming bait. From these observations, we developed an index for the number of wild pigs, deer, and raccoons that consumed bait during feeding bouts as the maximum observed present/maximum observed consuming bait. This index provided an unbiased method for comparing among treatments, though it underestimated the true proportion of animals that accessed the bait stations.

We focused analyses of the field study data on wild pigs, white-tailed deer, and raccoons because these species were the primary visitors to the bait sites in this study area (Snow et al. 2016), and the only species we considered capable of accessing bait stations in this area. Respectively for each of these species, we extracted the response variable of the daily count of accessing events into the bait stations. Then for each species, we conducted 2 analyses to examine how the response variable was influenced by 1) the 3 bait-station treatments including plastic, metal, and control (i.e., no bait station) and 2) the 3 bait-station manipulations including lid completely open, lid propped open, and lid closed. We used Poisson generalized linear-effect models with log links and offsets of the maximum number of each species observed each day. We used the offsets to standardize the number of accesses into the bait stations by the maximum number of each species that visited the bait sites per day.

From the motion-activated cameras, we calculated the true proportion of animals that accessed the bait stations for the treatment nights with closed lids. We specifically focused on these nights to represent the final stage of the bait station when toxic bait would ultimately be offered. Finally, we compared temperatures among the treatment types by calculating the daily means and standard errors (SEs) of recorded temperatures from all bait stations by treatment type.

\section{RESULTS}

The average duration from first feeding until all food consumed in the pen studies ranged from 0:26 to 2:05 hr. For Phase 1 of the pen study, the average number of multianimal 
feeding events per trial was $40.6(\mathrm{SE}=6.0)$ and the average number of single-animal feeding events was 69.5 (SE $=12.3$ ). We found all trough lengths increased the number of multianimal feeding events compared with the shortest trough (Table 1); however, only the longest troughs (i.e., 1.1 and $1.9 \mathrm{~m}$ ) reduced the number of single-animal feeding events. For Phase 2, the average number of feedings per animal per trial was $10.1(\mathrm{SE}=1.3)$ and the average number of steals was $0.4(\mathrm{SE}=0.1)$. All of the trough arrangements allowed for similar frequency of feeding by wild pigs (Table 1); none of the arrangements appeared to reduce the frequency of animals aggressively stealing access.

From the field study, we recorded 1,335 feeding bouts by wild pigs, 1,294 by deer, and 191 by raccoons. On average, the maximum number of wild pigs recorded in a single image per feeding bout was $3.7(\mathrm{SE}=0.1)$, for deer was 1.6 $(\mathrm{SE}=0.02)$, and for raccoons was $1.6(\mathrm{SE}=0.07)$. We found that wild pigs accessed the metal bait stations less than the plastic bait stations, but accessed the bait at control sites more than the plastic bait stations (Table 2; Fig. 4). Deer followed similar trends as wild pigs (Table 2). Raccoons accessed the plastic, metal, and control treatments equally.

Lowering the lids of the bait stations from completely open to propped open reduced access by wild pigs; however, access by wild pigs increased again after the lids were completely closed (Table 2; Fig. 4). We could not fit a model for deer because deer totally stopped accessing the bait stations after the lids changed from completely open to propped open (Fig. 4). Access by raccoons was the most variable of all species (Fig. 4), but was reduced once the lids were completely closed (Table 2). We recorded visitation to study sites by other wildlife in the area including wild turkeys (Meleagris gallopavo), rodents, coyotes (Canis latrans), Virginia opossums (Didelphis virginiana), gray foxes (Urocyon cinereoargenteus), squirrels (Sciurus spp.), cottontail rabbits (Sylvilagus spp.), black-tailed jackrabbits, (Lepus californicus), nine-banded armadillos (Dasypus novemcinctus), and striped skunks (Mephitis mephitis). Although these animals visited study sites and occasionally fed from bait stations when the lids were open, no feeding by these species was documented after lids were closed.

From the motion-activated images, we found that $46 \%$ $(n=65)$ wild pigs accessed the plastic bait station on the first night the lids were completely closed, and $80 \%(n=41)$ accessed the second night. At those same sites, 0 of 4 deer accessed during the first night and 0 of 7 during the second night. We also found that 5 of 6 raccoons accessed closed lids during the first night and 1 of 6 during the second night.

Temperatures of the bait stations averaged $26.9^{\circ} \mathrm{C}$ $(\mathrm{SE}=0.2)$ for the plastic, $26.3^{\circ} \mathrm{C}(\mathrm{SE}=0.2)$ for the metal, and $25.3^{\circ} \mathrm{C}(\mathrm{SE}=0.2)$ at the control sites (i.e., ambient temp). Mean maximum temperatures reached by both metal and plastic bait stations were $36.2^{\circ} \mathrm{C}$ and $36.3^{\circ} \mathrm{C}$, respectively, and were only approximately $3^{\circ} \mathrm{C}$ warmer than ambient temperatures, peaking between the hours of 1300 and 1700 .

\section{DISCUSSION}

We developed a bait station that enabled access by the majority of wild pigs, excluded the majority of the most ubiquitous nontarget species, and was practical for field use. We evaluated each design element in a stepwise fashion, refining the design based on responses of wild pigs to specific design features. British agriculture feeding standards for domestic swine troughs recommend $0.28 \mathrm{~m}$ of feeding space/ 90-kg pig, though $0.25 \mathrm{~m}$ was determined insufficient for simultaneous feeding by 6 pigs without disruptive aggression (Baxter 1983). The 1.1-m and $1.9-\mathrm{m}$ troughs in our evaluation performed similarly for groups of 5 wild pigs, suggesting that wild pigs were satisfied with approximately $0.22 \mathrm{~m} /$ animal. We found the $1.9-\mathrm{m}$ trough offered no clear advantage over the 1.1-m length, and was unwieldy for deployment by a single operator; thus, we selected the $1.1-\mathrm{m}$ length for use in the field.

Surprisingly to us, the arrangement of a pair of troughs had little influence on access by wild pigs in this study because previously, feeders with multiple feeding locations demonstrated improved access and performance over single-space feeders in feeding domestic pigs (Walker and Overton 1988).

Table 1. Regression coefficients $(\beta)$ and $95 \%$ confidence intervals (CIs) from categorical predictor variables of trough length (Phase 1), and trough arrangement (Phase 2) both estimated using a Poisson generalized model with a log link, respectively. The models evaluated the effects of trough length and trough arrangement on the feeding behaviors of captive invasive wild pigs during June 2015 at the Kerr Wildlife Management Area, Hunt, Texas, USA.

\begin{tabular}{|c|c|c|c|c|c|c|c|}
\hline & \multirow[b]{2}{*}{ Treatment $^{\mathbf{a}}$} & \multicolumn{3}{|c|}{ Count of multianimal feeding events } & \multicolumn{3}{|c|}{ Count of single-animal feeding events } \\
\hline & & $\beta$ & Upper CI & Lower CI & $\beta$ & Upper CI & Lower CI \\
\hline \multirow[t]{6}{*}{ Phase 1: trough length } & Intercept & -3.46 & -3.82 & -3.13 & -0.71 & -0.80 & -0.62 \\
\hline & $0.6 \mathrm{~m}$ & 1.96 & 1.59 & 2.35 & -0.07 & -0.21 & 0.07 \\
\hline & $1.1 \mathrm{~m}$ & 2.71 & 2.36 & 3.10 & -0.41 & -0.60 & -0.24 \\
\hline & $1.9 \mathrm{~m}$ & 2.21 & 1.86 & 2.59 & -1.16 & -1.36 & -0.97 \\
\hline & & \multicolumn{3}{|c|}{ Count of accessing trough events } & \multicolumn{3}{|c|}{ Count of stealing access to trough events } \\
\hline & Treatment $^{\mathrm{b}}$ & $\beta$ & Upper CI & Lower CI & $\beta$ & Upper CI & Lower CI \\
\hline \multirow[t]{3}{*}{ Phase 2: trough arrangement } & Intercept & -1.24 & -1.42 & -1.06 & -4.64 & -5.81 & -3.80 \\
\hline & Back-to-back & 0.20 & -0.03 & 0.43 & 0.55 & -0.57 & 1.85 \\
\hline & Back-to-back with divider & -0.01 & -0.24 & 0.25 & -0.46 & -2.09 & 1.04 \\
\hline
\end{tabular}

\footnotetext{
${ }^{a}$ The reference category of trough length was the shortest trough $(0.3 \mathrm{~m})$.

$\mathrm{b}$ The reference category of trough arrangement was the separated troughs (i.e., pair of troughs situated $3 \mathrm{~m}$ apart and opening to a shared central point).
} 
Table 2. Regression coefficients $(\beta)$ and $95 \%$ confidence intervals (CIs) from categorical predictor variables of bait-station type, and manipulation of baitstation lids both estimated using a Poisson generalized linear model with a log link, respectively. The models evaluated the effects of bait-station type (i.e., plastic, metal, or control), and manipulation of the lids (open, propped, or closed) on the number of animals gaining access to whole-kernel corn inside during September 2015 on Camp Bullis, San Antonio, Texas, USA.

\begin{tabular}{|c|c|c|c|c|c|c|c|c|}
\hline & \multicolumn{4}{|c|}{ Type of bait station ${ }^{a}$} & \multicolumn{4}{|c|}{ Manipulation of bait-station lids ${ }^{b}$} \\
\hline & Treatment & $\beta$ & Upper CI & Lower CI & Treatment & $\beta$ & Upper CI & Lower CI \\
\hline \multirow[t]{3}{*}{ Invasive wild pigs } & Intercept & -1.27 & -1.33 & -1.19 & Intercept & -1.93 & -2.05 & -1.83 \\
\hline & Metal & -0.58 & -0.75 & -0.42 & Open & 1.01 & 0.87 & 1.15 \\
\hline & Control & 1.11 & 1.02 & 1.21 & Closed & 0.67 & 0.42 & 0.91 \\
\hline \multirow[t]{3}{*}{ Deer } & Intercept & -2.64 & -2.89 & -2.43 & Intercept & \multirow{3}{*}{\multicolumn{3}{|c|}{$\begin{array}{c}\text { Could not estimate. No deer accessed with } \\
\text { lids propped. }\end{array}$}} \\
\hline & Metal & -1.05 & -1.87 & -0.39 & Open & & & \\
\hline & Control & 2.17 & 1.93 & 2.42 & Closed & & & \\
\hline \multirow[t]{3}{*}{ Raccoons } & Intercept & -0.68 & -0.86 & -0.50 & Intercept & -0.60 & -0.82 & -0.40 \\
\hline & Metal & 0.04 & -0.53 & 0.40 & Open & 0.18 & -0.19 & 0.54 \\
\hline & Control & 0.29 & -0.28 & 0.80 & Closed & -1.21 & -2.02 & -0.55 \\
\hline
\end{tabular}

a The reference category of type was plastic.

b The reference category of manipulation was lids propped open at $\sim 5.25 \mathrm{~cm}$.

We observed some dominant animals displacing subordinates by aggressively moving between the troughs in the pens with separated troughs, but did not observe this with the back-to-back troughs. The divider between the back-to-back troughs did not decrease aggressive behaviors possibly because the lids on the troughs without a divider served the same purpose of limiting the view of animals approaching the bait station. For these reasons, we selected the back-toback troughs without a divider for operational use.

Along with other nontarget wildlife species visiting bait stations, white-tailed deer were completely excluded from accessing the bait station once the lids were closed. Further,

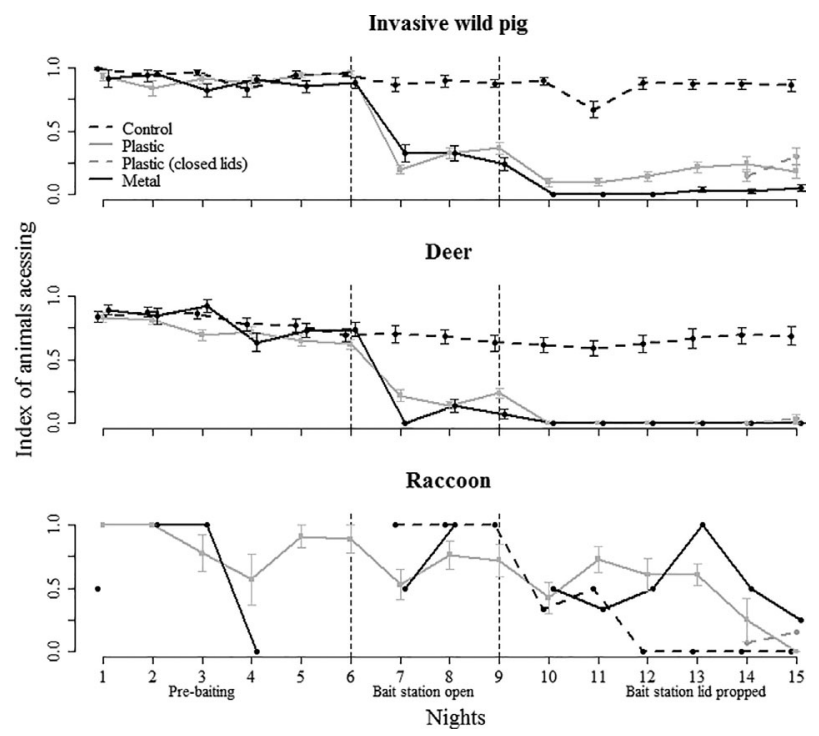

Figure 4. Index of invasive wild pig, white-tailed deer, and raccoon access to bait stations in field trials in September 2015, Camp Bullis, San Antonio, Texas, USA. This index (max. no. of animals observed accessing the bait station/max. no. of animals observed visiting the bait station during a feeding bout) represents the minimum proportion of animals gaining access to bait stations as recorded by time-lapse imagery. Control sites provided ad libitum whole-kernel corn and plastic and metal refers to bait-station construction. Plastic with closed lids were the same as plastic though the lids were completely closed on the last 2 nights of the study. we found that raccoons were capable of opening the lids to access bait without any added resistance to open lids. However, addition of $13.6 \mathrm{~kg}$ of magnetic resistance to the lids should minimize potential for access to bait stations by raccoons (Snow et al. 2017c). When deploying bait stations in black bear range, minimizing risk to black bears could be facilitated by active monitoring with cameras to inform relocation of bait stations if bears visit or will require more specialized bait-station design (Campbell et al. 2013).

During the field test, we found that plastic bait stations outperformed metal bait stations in several ways. First, the proportion of individuals feeding from bait stations was greater for plastic bait stations. Second, the weight of the lids and pressure placed on heads of animals while feeding was $4.1 \mathrm{~kg}$ for plastic and $7.0 \mathrm{~kg}$ for metal, which may have contributed to the differences in proportion of animals feeding from them. Third, the plastic bait stations were more user-friendly in that they were more adjustable and easier to carry to remote sites. The temperatures within both plastic and metal bait stations exceeded that of ambient temperatures, and reached similar maximum temperatures.

Our findings showed that up to $80 \%$ of wild pigs visiting bait stations were able to successfully access them after the lids were closed. If $80 \%$ of wild pigs consume lethal doses of a toxic bait from a bait stations in practice, the removal rate would exceed the $52 \%$ stated to be high enough to effectively stop population growth and reduce populations of wild pigs (Hone 2007), but this assumes a high level of population exposure to the bait stations. Control sites without bait stations had greater levels of consumption, demonstrating that bait stations reduced feeding by wild pigs. Previous designs of bait stations experienced similar declines in consumption when attempting to exclude nontarget animals (Long et al. 2010, Massei et al. 2010, Campbell et al. 2013). These results reflect those of a previous study where $73 \%$ of captive wild pigs accessed a similar bait station with $18.1 \mathrm{~kg}$ of magnetic resistance holding the lids closed (Snow et al. 2017c). Considering that wild pigs developed learned behaviors for accessing bait station in previous studies, we anticipate the next step of 
refining a bait delivery strategy will further improve efficiency and overall consumption.

\section{MANAGEMENT IMPLICATIONS}

We recommend further development of a plastic bait station constructed of 2 back-to-back troughs, $1.1 \mathrm{~m}$ in length, without a divider to achieve feeding the largest proportion of wild pigs. Overall, up to $80 \%$ wild pigs accessed the bait stations, providing promising results for the eventual delivery of a toxic bait to control invasive populations. Deer were excluded by closing the lids, but resistance on the lids will be necessary to exclude raccoons. Future steps in development of a bait station should focus on baiting strategies that match the learning potential to provide access to the bait stations to the maximum proportion of wild pigs present while incorporating resistance on lids to exclude raccoons. This bait-station design would not be appropriate for operational use in areas where more formidable nontargets such as black bears are a concern and more robust wild pig-specific bait stations and monitoring will be required.

\section{ACKNOWLEDGMENTS}

We are grateful to the National Wildlife Research Center (NWRC) for logistical support. Additional thanks to Texas Parks and Wildlife Department and Joint Base San Antonio for allowing access to study areas and wild pigs for this study. We also thank the following for assisting with and providing supplies for the project: C. Martin, C. Kohler, J. Fischer, E. VanNatta, C. Blass, L. Staples, and S. Humphrys. Funding and support of this research were provided by the NWRC, the Association of Fish \&Wildlife Agencies, and the Animal and Plant Health Inspection Service National Feral Swine Damage Management Program. We thank Associate Editor S. Haskell and anonymous reviewers for their comments on this manuscript. Mention of commercial products or companies does not represent an endorsement by the U.S. government.

\section{LITERATURE CITED}

Angermeier, W., J. Mclean, D. Minvielle, and C. Grue. 1987. Foodrewarded operant learning in the opossum. Bulletin of the Psychonomic Society 25:23-26.

Bailey, R. G. 1980. Description of the ecoregions of the United States. U.S. Department of Agriculture, Forest Service, Washington, D.C., USA.

Bailey, R. G., editor. 1998. Ecoregions. Springer, New York, New York, USA.

Ballesteros, C., C. Gortázar, M. Canales, J. Vicente, A. Lasagna, J. A. Gamarra, R. Carrasco-García, and J. De la Fuente. 2009. Evaluation of baits for oral vaccination of European wild boar piglets. Research in Veterinary Science 86:388-393.

Baxter, M. 1983. Feeding and aggression in pigs. Applied Animal Ethology 11:74-75.

Bengsen, A. J., L. K.-P. Leung, S. J. Lapidge, and I. J. Gordon. 2011. Target-specificity of feral pig baits under different conditions in a tropical rainforest. Wildlife Research 38:370-379.

Bevins, S. N., K. Pedersen, M. W. Lutman, T. Gidlewski, and T. J. Deliberto. 2014. Consequences associated with the recent range expansion of nonnative feral swine. BioScience 64:291-299.

Boersen, M. R., J. D. Clark, and T. L. King. 2003. Estimating black bear population density and genetic diversity at Tensas River, Louisiana using microsatellite DNA markers. Wildlife Society Bulletin 31:197-207.
Burton, J. L., J. D. Westervelt, and S. Ditchkoff. 2013. Simulation of wild pig control via hunting and contraceptives. Final report ERDC/CERL TR- 13-21. U.S. Army Engineer Research and Development Center, Construction Engineering Research Laboratory. http://cdm16021. contentdm.oclc.org/utils/getdownloaditem/collection/p266001coll1/id/ 3575/filename/3576.pdf/mapsto/pdf. Accessed 11 Jan 2018.

Campbell, T. A., J. A. Foster, M. J. Bodenchuk, J. D. Eisemann, L. Staples, and S. J. Lapidge. 2013. Effectiveness and target-specificity of a novel design of food dispenser to deliver a toxin to feral swine in the United States. International Journal of Pest Management 59:197-204.

Campbell, T. A., and D. B. Long. 2009. Feral swine damage and damage management in forested ecosystems. Forest Ecology and Management 257:2319-2326.

Campbell, T. A., D. B. Long, L. R. Bazan, B. V. Thomsen, S. RobbeAusterman, R. B. Davey, L. A. Soliz, S. R. Swafford, and K. C. VerCauteren. 2011a. Absence of Mycobacterium bovis in feral swine (Sus scrofa) from the southern Texas border region. Journal of Wildlife Diseases 47:974-978.

Campbell, T. A., D. B. Long, and G. Massei. 2011b. Efficacy of the BoarOperated-System to deliver baits to feral swine. Preventive Veterinary Medicine 98:243-249.

Cowled, B., S. Lapidge, M. Smith, and L. Staples. 2008. Vaccination of feral pigs (Sus scrofa) using iophenoxic acid as a simulated vaccine. Australian Veterinary Journal 86:50-55.

Day, J., I. Kyriazakis, and A. Lawrence. 1995. The effect of food deprivation on the expression of foraging and exploratory behaviour in the growing pig. Applied Animal Behaviour Science 42:193-206.

DeBoer, T. S., and D. D. Diamond. 2006. Predicting presence-absence of the endangered golden-cheeked warbler (Dendroica chrysoparia). Southwestern Naturalist 51:181-190.

Feldhamer, G. A., and B. E. McCann. 2004. Dental anomalies in wild and domestic Sus scrofa in Illinois. Acta Theriologica 49:139-143.

Ferretti, F., A. Sforzi, J. Coats, and G. Massei. 2014. The BOS ${ }^{\mathrm{TM}}$ as a species-specific method to deliver baits to wild boar in a Mediterranean area. European Journal of Wildlife Research 60:555-558.

Focardi, S., F. Morimando, S. Capriotti, A. Ahmed, and P. Genov. 2015. Cooperation improves the access of wild boars (Sus scrofa) to food sources. Behavioural Processes 121:80-86.

Frey, D. 2017. Is Kaput Kaput? The Wildlife Professional September/ October:38-40.

Held, S., M. Mendl, C. Devereux, and R. W. Byrne. 2000. Social tactics of pigs in a competitive foraging task: the 'informed forager' paradigm. Animal Behaviour 59:569-576.

Held, S., M. Mendl, C. Devereux, and R. W. Byrne. 2002. Foraging pigs alter their behaviour in response to exploitation. Animal Behaviour 64:157-165.

Hone, J. 2007. Wildlife damage control. CSIRO, Clayton, Australia.

Ivan, J. S., and E. S. Newkirk. 2015. CPW Photo Warehouse: a custom database to facilitate archiving, identifying, summarizing and managing photo data collected from camera traps. Methods in Ecology and Evolution 7:499-504.

Keiter D. A, J. J. Mayer, and J. C. Beasley. 2016. What is in a "common" name? A call for consistent terminology for nonnative Sus scrofa. Wildlife Society Bulletin 40:384-387.

Kittawornrat, A., and J. J. Zimmerman. 2011. Toward a better understanding of pig behavior and pig welfare. Animal Health Research Reviews 12:25-32.

Lapidge, S., J. Wishart, L. Staples, K. Fagerstone, T. Campbell, and J. Eisemann. 2012. Development of a feral swine toxic bait (Hog-Gone ${ }^{\text {) }}$ and bait hopper $\left(\mathrm{Hog}-\mathrm{Hopper}^{\mathrm{TM}}\right)$ in Australia and the USA. University of Nebraska, Lincoln, USA

Long, D. B., T. A. Campbell, and G. Massei. 2010. Evaluation of feral swine-specific feeder systems. Rangelands 32:8-13.

Massei, G., J. Coats, R. Quy, K. Storer, and D. P. Cowan. 2010. The BoarOperated-System: a novel method to deliver baits to wild pigs. Journal of Wildlife Management 74:333-336.

Mayer, J., and I. L. Brisbin. 2009. Wild pigs: biology, damage, control techniques and management. Savanna River Site, Aiken, South Carolina, USA.

McClure, M. L., C. L. Burdett, M. L. Farnsworth, M. W. Lutman, D. M. Theobald, P. D. Riggs, D. A. Grear, and R. S. Miller. 2015. Modeling and mapping the probability of occurrence of invasive wild pigs across the contiguous United States. PLoS ONE 10:e0133771. 
McLean, P. K., and M. R. Pelton. 1994. Estimates of population density and growth of black bears in the Smoky Mountains. Bears: Their Biology and Management 9:253-261.

National Climatic Data Center. 2017. Climate data online. https://www. ncdc.noaa.gov/cdo-web/. Accessed 17 May 2017.

Nielsen, B. L., A. B. Lawrence, and C. T. Whittemore. 1995. Effect of group size on feeding behaviour, social behaviour, and performance of growing pigs using single-space feeders. Livestock Production Science 44:73-85.

Nielsen, B. L., A. B. Lawrence, and C. T. Whittemore. 1996. Feeding behaviour of growing pigs using single or multi-space feeders. Applied Animal Behaviour Science 47:235-246.

Pelton, M., and F. Van Manen. 1994. Distribution of black bears in North America. Eastern Workshop on Black Bear Research and Management 12:133-138.

Pimentel, D. 2007. Environmental and economic costs of vertebrate species invasions into the United States. Pages 2-8 in G. W. Witmer, W. C. Pitt, and K. A. Fagerstone, editors. Managing vertebrate invasive species: proceedings of an international symposium. U.S. Department of Agriculture, Animal and Plant Health Inspection Service, Wildlife Services, National Wildlife Research Center, Fort Collins, Colorado, USA.

Seaman, S. C., N. K. Waran, G. Mason, and R. B. D'Eath. 2008. Animal economics: assessing the motivation of female laboratory rabbits to reach a platform, social contact and food. Animal Behaviour 75:31-42.

Seward, N. W., K. C. VerCauteren, G. W. Witmer, and R. M. Engeman. 2004. Feral swine impacts on agriculture and the environment. Sheep and Goat Research 12:34-40.

Shapiro, L., C. Eason, C. Bunt, S. Hix, P. Aylett, and D. MacMorran. 2016. Efficacy of encapsulated sodium nitrite as a new tool for feral pig management. Journal of Pest Science 89:489-495.

Snow, N. P., J. A. Foster, J. C. Kinsey, S. T. Humphrys, L. D. Staples, and K. C. VerCauteren. 2017a. Development of toxic bait to control invasive wild pigs and reduce damage. Wildlife Society Bulletin 40:256-263.
Snow, N. P., J. M. Halseth, M. J. Lavelle, T. E. Hanson, C. R. Blass, J. A. Foster, S. T. Humphrys, L. D. Staples, D. G. Hewitt, and K. C. VerCauteren. 2016. Bait preference of free-ranging feral swine for delivery of a novel toxicant. PLoS ONE 11:e0146712.

Snow, N. P., M. A. Jarzyna, and K. C. VerCauteren. 2017b. Interpreting and predicting the spread of invasive wild pigs. Journal of Applied Ecology 54:2022-2032.

Snow, N. P., M. J. Lavelle, J. Halseth, C. Blass, J. Foster, and K. VerCauteren. 2017c. Strength testing of raccoons and invasive wild pigs for a species-specific bait station. Wildlife Society Bulletin 40:264-270. https://doi.org/10.1002/wsb.756

Stankus, T. 2012. Razorbacks: feral pigs as agricultural pests, disruptors of ecosystems, reservoirs of contagion, and favored game for sport and subsistence hunters: a review of the literature, 2005-2011. Journal of Agricultural and Food Information 13:283-301.

Thurfjell, H., J. P. Ball, P.-A. Åhlén, P. Kornacher, H. Dettki, and K. Sjöberg. 2009. Habitat use and spatial patterns of wild boar Sus scrofa (L.): agricultural fields and edges. European Journal of Wildlife Research 55:517-523.

Walker, A. J., and D. C. Overton. 1988. Comparison of the performance of finishing pigs fed ad libitum from either conventional or single-place feeders. Pages 121-122 in I. M. Forbes, M. A. Varley, and T. L. J. Lawrence, editors. The voluntary food intake of pigs. British Society of Animal Production, Occasional Publication no. 13, Edinburgh, United Kingdom.

Wyckoff, A. C., S. E. Henke, T. A. Campbell, D. G. Hewitt, and K. C. VerCauteren. 2009. Feral swine contact with domestic swine: a serologic survey and assessment of potential for disease transmission. Journal of Wildlife Diseases 45:422-429.

Associate Editor: Haskell. 